\title{
ACCESO A LA INFORMACIÓN AMBIENTAL
}

\section{ACCESS TO ENVIRONMENTAL INFORMATION}

\author{
FELIPE RAMÍREZ PARADA*
}

Un aspecto fundamental para la concreción de una política y una reforma estructural ambiental exitosa, que hasta hace poco se encontraba ausente en nuestro país, es el acceso a la información ambiental. El ejercicio de los derechos contemplados en la Constitución y las distintas normas que hacen alusión al medio ambiente, exige la existencia de ciudadanos informados, con acceso a los documentos, resoluciones, estudios y antecedentes en poder de las autoridades que tienen competencia en la fiscalización y evaluación de estudios o declaraciones de impacto ambiental, en la dictación de normas de calidad ambiental o de emisión, o en la administración de los instrumentos de gestión ambiental.

De esta forma, la Ley No 20.417 -promulgada el 12 de enero del 2010- que crea el Ministerio y la Superintendencia del Medio Ambiente, así como el Servicio de Evaluación Ambiental (SEA), modifica, entre otros, el ar-

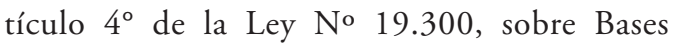
Generales del Medio Ambiente (LSBGMA), señalando que: "Es deber del Estado facilitar la participación ciudadana, permitir el acceso a la información ambiental y promover campañas educativas destinadas a la protección del medio ambiente", e incorpora, en su Título Segundo, un nuevo párrafo $3^{\circ}$ bis "Del Acceso a la Información Ambiental”. Si bien lo anterior refuerza un importante principio -la publicidad de la información de los órganos del Estado-, por primera vez se destaca la importancia del ejercicio de un derecho fundamen$\mathrm{tal}^{1}$ respecto a una materia de interés público

\footnotetext{
* Abogado, Asesor Jurídico del Consejo para la Transparencia.

${ }^{1}$ Reconocido así en diversos instrumentos internacionales. Véase "Claude Reyes y otros vs. Chile" (2006). Sentencia de la Corte Interamericana de Derechos Humanos en contra del Estado de Chile, por vulnerar
}

más o menos reciente. Así, dentro de este párrafo, el artículo 31 bis establece que: "Toda persona tiene derecho a acceder a la información de carácter ambiental que se encuentre en poder de la Administración, de conformidad a lo señalado en la Constitución Política de la República y en la ley No 20.285 sobre Acceso a la Información Pública" (LAIP). Es decir, el acceso a la información de carácter ambiental que garantiza esta nueva norma, depende del ejercicio del derecho fundamental establecido en el artículo $8^{\circ}$ de la Constitución, los instrumentos que contempla la LAIP y la supervigilancia de la institución creada para velar por el cumplimiento de esta última, el Consejo para la Transparencia.

Ahora, aun cuando nuestra Constitución y la LAIP -promulgada el 20 de agosto del año 2008 y que entró en vigencia 8 meses más tarde- no distinguen entre acceso a información pública en general y acceso a información ambiental -como sí lo hacen otras leyes de acceso a la información en diversos países a partir de la celebración del Convenio de Aarhus²-, esta última ha constituido una herramienta fundamental para promover el control y la participación ciudadana en la gestión ambiental que desarrollan un sinnúmero de órganos y servicios de la Administración del Estado.

Una muestra de esto es que, de acuerdo a la información entregada por la Comisión de Probidad y Transparencia, perteneciente al Ministerio Secretaría General de la Presidencia y

el derecho de acceso a la información pública. Disponible en http://www.consejotransparencia.cl/claudereyes-y-otros-vs-chile/consejo/2009-04-17/ 165943.html, sitio consultado en octubre de 2010.

2 Convención sobre el acceso a la información, la participación del público en la toma de decisiones y el acceso a la justicia en asuntos ambientales. Aarhus (Dinamarca), 25 de junio de 1998. 
encargada de coordinar el cumplimiento de la LAIP por parte de los órganos de Gobierno, a solo 3 meses de la entrada en vigencia de la ley en comento, ya se habían presentado 151 solicitudes de información a la Corporación Nacional del Medio Ambiente (CONAMA), lo que representa un número mayor al total de solicitudes de información recibidas en el mismo periodo por Ministerios como los de Relaciones Exteriores, Minería y Agricultura, entre otros. Por su parte, dentro de este último, durante los 3 primeros meses de vigencia, de un total de 114 solicitudes de información presentadas a los 5 servicios que lo componen, 64 de ellas fueron dirigidas al Servicio Agrícola Ganadero (SAG), que tiene -entre otros objetivos estratégicos- el de proteger, conservar y acrecentar el estado de los recursos naturales renovables. En la actualidad, y con información recogida por la mencionada comisión hasta septiembre de 2010 , se han presentado 1.222 solicitudes de información a CONAMA, 558 solicitudes al Ministerio de Agricultura -de las cuales 355 fueron dirigidas al SAG-, 635 solicitudes al Servicio Nacional de Pesca y otras tantas a entidades como la Corporación Nacional Forestal (CONAF) o la Dirección Nacional de Aguas ${ }^{3}$.

Si bien estas cifras reflejan en parte el creciente interés público en los asuntos medioambientales, tomando en cuenta que el número de requerimientos en las instituciones mencionadas sobrepasa claramente el promedio de 171 solicitudes de información recibidas por los distintos organismos de la Administración ${ }^{4}$, es la novedad y el desconocimiento de esta inédita apertura pública la que sin duda a influido en que la estadística respecto a dichas entidades no sea aún más contundente. Sin embargo, con la dictación de la Ley $\mathrm{N}^{\circ}$

\footnotetext{
${ }^{3}$ De acuerdo al informe de avance de seguimiento de septiembre de 2010 de la Comisión de Probidad y Transparencia, se han presentado un total de 47.731 solicitudes de información en los 278 servicios que forman parte de la Administración Central.

${ }^{4}$ El funcionamiento de la Superintendencia del Medio Ambiente está supeditado a la aprobación del proyecto de ley que crea los tribunales ambientales (Boletín No 6747-12).
}

20.417 y el interés que concita la creación de una nueva institucionalidad, se espera que la demanda por información de carácter ambiental, esto es, aquella que sirve de fundamento para el pronunciamiento de actos administrativos que se refieren al estado de los componentes ambientales, así como de los factores que inciden en él y las medidas adoptadas para preservarlo, aumente considerablemente. Refuerza lo anterior, el hecho de que, de acuerdo artículo 31 ter de la modificada LSBGMA, el Ministerio del Medio Ambiente tiene dentro de sus funciones la de administrar un Sistema Nacional de Información Ambiental, desglosado regionalmente, en el cual se indicará, entre otras informaciones:

- Los textos de tratados, convenios y acuerdos internacionales, así como las leyes, reglamentos y demás actos administrativos sobre medio ambiente o relacionados con él;

- Los informes sobre el estado del medio ambiente a nivel nacional, regional y local que cada cuatro años debe elaborar el Ministerio, así como los reportes anuales sobre la misma materia;

- Las autorizaciones administrativas asociadas a actividades que pueden tener un efecto significativo sobre el medio ambiente;

- La lista de las autoridades públicas que disponen de información de contenido ambiental y que debe ser públicamente accesible;

- Los dictámenes de la Contraloría General de la República y las sentencias definitivas de los Tribunales de Justicia recaídos en materias ambientales $\mathrm{y}$,

- Toda otra decisión o resolución de carácter general emanada de autoridad recaída en asuntos ambientales.

Por su parte, la futura Superintendencia del Medio Ambiente, que será objeto de más de un requerimiento de información vinculado con su función fiscalizadora, administrará y mantendrá un registro público de resoluciones de calificación ambiental -actualizado semestralmenteen el que se identificará el proyecto, su localiza- 
ción geográfica, la fecha de su otorgamiento, el titular, el objetivo del mismo y su estado.

Por último, el nuevo Servicio de Evaluación Ambiental (SEA), cuya principal función consiste en reemplazar a CONAMA y a las respectivas Corporaciones Regionales, en la administración del Sistema de Evaluación de Impacto Ambiental (SEIA), tiene, de acuerdo al nuevo artículo 81 de la LSBGMA, la tarea de administrar un sistema de información sobre permisos y autorizaciones de contenido ambiental, el que deberá estar abierto al público en el sitio web del servicio y un sistema de información de líneas de bases de los proyectos sometidos al SEIA, de acceso público y georreferenciado. Además, el SEA debe fomentar y facilitar la participación ciudadana en la evaluación de proyectos por lo que, si consideramos que de acuerdo a esta misma norma la participación ciudadana comprende los derechos a acceder y conocer el expediente físico o electrónico de la evaluación, formular observaciones y obtener respuesta fundada de ellas, nos encontramos con un servicio que seguramente estará en la mira de la ciudadanía.

Todo lo anterior, pone de manifestó la gran cantidad de información de interés público que dichas instituciones administrarán, no solo de relevancia ambiental, sino también comercial y anticipa claramente la frecuencia y constancia con que los nuevos organismos "verdes" serán requeridos. Sin embargo, en un principio la recepción de solicitudes de infor- mación a estas nuevas instituciones debió ser postergada y asumida por CONAMA, ya que a una semana de asumir el cargo (17 de marzo de 2010) y en vista de la grave situación en que se encontraba el país tras el terremoto del 27 de febrero, la nueva Ministra del Medio Ambiente dio instrucciones para retirar de la Contraloría los Decretos con Fuerza de Ley (DFL) que implementaban la nueva institucionalidad ambiental. Afortunadamente, luego de dos meses de un riguroso proceso de análisis y evaluación, los DFL que fijaban los organigramas de las nuevas entidades fueron reingresados y posteriormente aprobados por el órgano contralor, lo que ha permitido que a partir del 1 de octubre de 2010, tanto el Ministerio del Medio Ambiente como el SEA se encuentren en funciones 5 .

Finalmente, este necesario rediseño institucional y la creciente demanda por información, no solo plantean un serio desafío de gestión para estas nuevas instituciones $-y$ otras que disponen de información ambiental-, ya que el mencionado Consejo para la Transparencia deberá adecuarse a un significativo aumento en la presentación de reclamos por denegación de acceso a la información ${ }^{6}$, pues según el nuevo artículo 31 quáter de la LSBGMA: "Cualquier persona que se considere lesionada en su derecho a acceder a la información ambiental, podrá recurrir ante la autoridad competente, de conformidad con lo señalado en la ley No 20.285, sobre Acceso a la Información Pública".

\footnotetext{
${ }^{5}$ Hasta septiembre de 2010 , se han presentaron 18 reclamos por denegación de acceso a la información en contra de CONAMA, 21 reclamos en contra del SAG, 11 reclamos en contra de CONAF, 8 reclamos en contra de SERNAPESCA y otros tantos por denegación de información de carácter ambiental (Fuente: Consejo para la Transparencia).
} 
